\title{
The COMMIDO
}

\section{Combined Operation Magnifiers and Miniature Indirect Ophthalmoscope}

\author{
L. PERICIC, G. W. GROGK, J.-M. PAREL, AND P. N. HENDERSON
}

From the Melbourne University Department of Ophthalmology and the Ophthalmic Research Institute of Australia, at the Royal Victorian Eye and Ear Hospital, Melbourne, Australia

A miniature binocular indirect ophthalmoscope is described, incorporating magnification. It is an improved version of the simple instrument reported by Crock, Galbraith, and Parel (1969). Although the problem of combining magnification with binocular indirect ophthalmoscopy was then considered, an entirely satisfactory technical solution was not achieved. That solution has now been found and the resulting instrument (Fig. I) has withstood clinical testing over the past 2 years. Additional design features include a new light-source and an improved battery pack, providing greatly increased illumination. Rucker's excellent historical account of the ophthalmoscope does not mention the optical combinations described here (Rucker, I972).

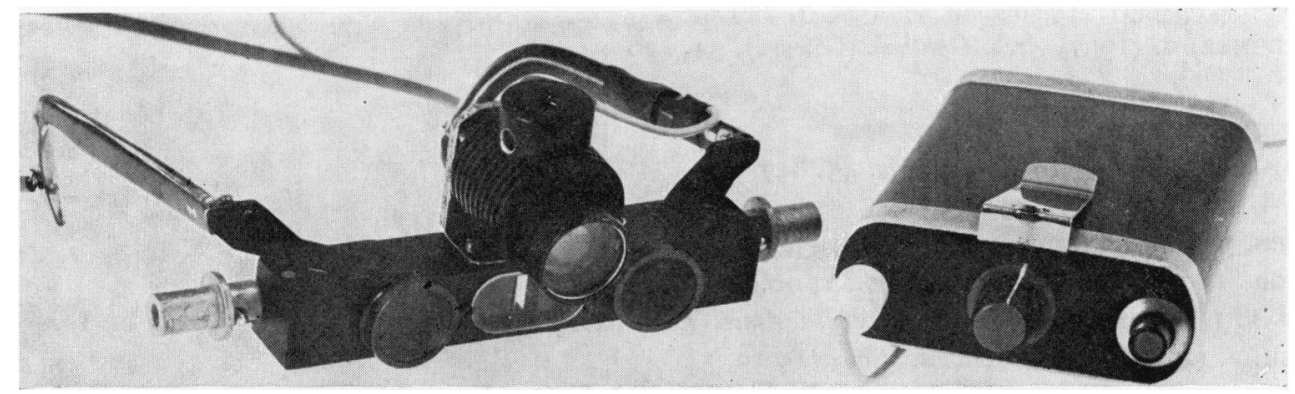

FIG. I General view of COMMIDO and rechargeable battery pack

\section{Description}

The instrument is attached to spectacle side-arms. A major optical design feature is the provision of visual pathways for both indirect ophthalmoscopy and a magnifying loupe. The change between normal and magnified views is effected simply and rapidly by a slide, controlled through projecting rods. Magnification is obtained by pushing the rods inwards. Sterile caps may be fitted to them for theatre use.

The pathways in an indirect ophthalmoscope are convergent. Folding the path by surface mirrors avoids the inevitable distortions and degradations of the image caused by prisms and reduces the total weight of the instrument by a factor of 12 per cent. The stereopsis angle is $3.5^{\circ}$ (Fig. 2A).

Magnification is provided by a pair of achromatic Galilean loupes. From the various magnifying powers and working distances available, $2.5 \times$ at a working distance of $300 \mathrm{~mm}$. was selected. In the present prototype, the front element was fixed and the rear element was mounted on a sliding carriage. This provided a stereopsis angle of $12.5^{\circ}$ and the best compromise in terms of weight ( $140 \mathrm{~g}$.) and 


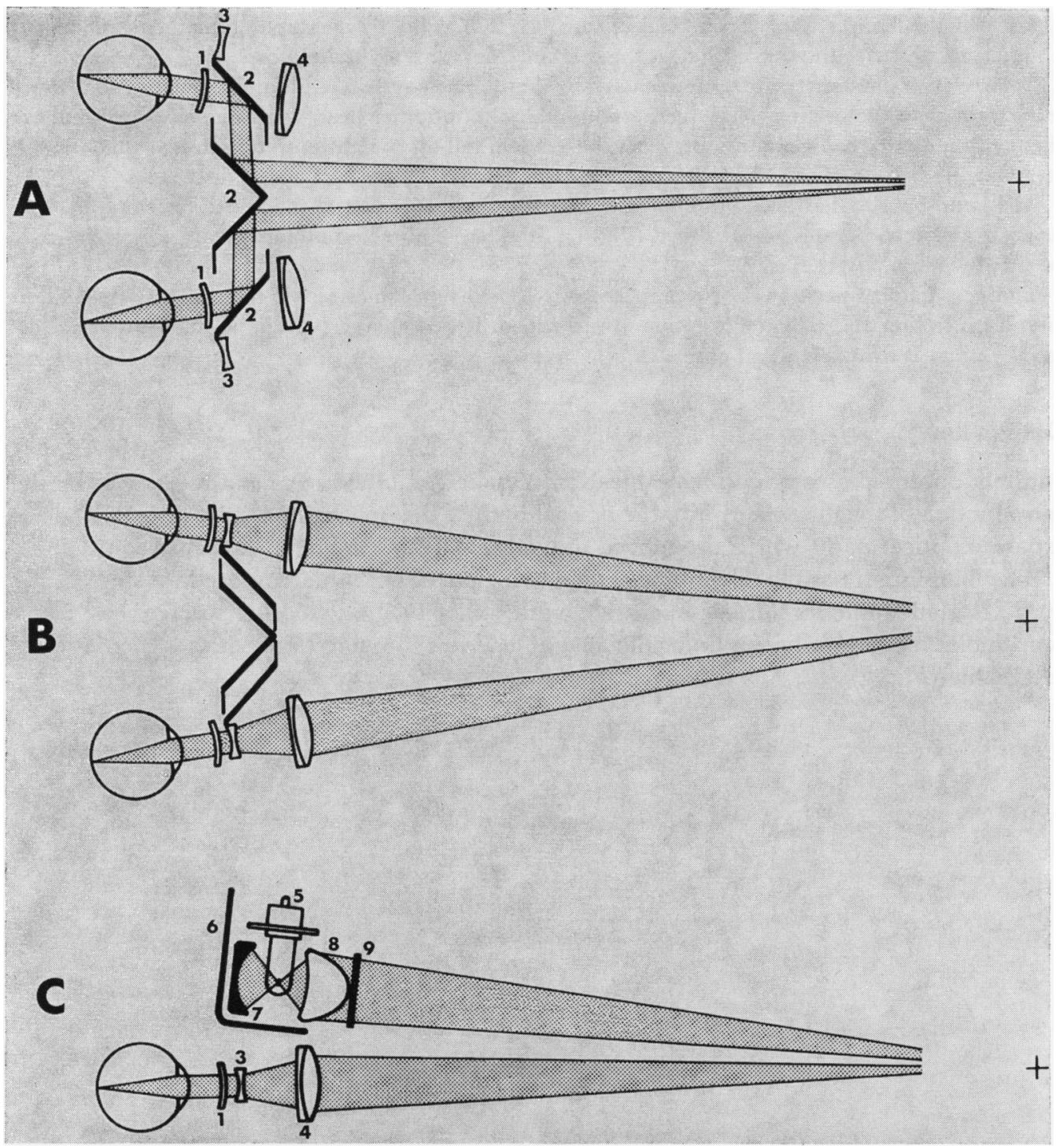

FIG. 2 COMMIDO optical schemata, showing the various optical elements and their relative positions, ophthalmoscopy $(A)$ and magnified viewing $(B)$. The illuminator $(C)$ viewed from the side
(1) prescription $R_{x}$
(2) surface-coated mirror
(6) heat shield
(3) (4) rear and front elements of Galilean loupes
(7) spherical surface-coated mirror
(5) quartz halogen lamp
(8) aspheric condenser
(9) heat filter

size reduction, but necessitated the construction of individual models according to pupillary separation (Fig. 2B). In the commercial version* the whole loupe slides, and the interpupillary distance may be pre-set to any requisite value. As both optical systems are virtually parafocal, the same light source is used (Fig. 2G). A spectacle correction may be placed in front of the entrance pupil.

While the original illuminator has been found to be satisfactory (Hilton, 1971), it was felt that an increase in its field and intensity would be useful. The light source was redesigned about a precentered

* Sola International Pty. Ltd., Adelaide, South Australia 
quartz halogen lamp, $\dagger$ using a spherical mirror to create a slightly overlapping filament image and a uniform field twice the size of that in the original miniature ophthalmoscope.

Comparative photometric measurements show that the new system emits approximately four times more light than the original instrument and double that of other head-worn models. Furthermore, the use of a quartz halogen lamp prevents the gradual fall-off of light output with age which is still an annoying feature of earlier models.

The lamp-housing has been redesigned to increase the dissipation of the added heat output. The housing also incorporates a heat shield (Fig. I). Standard indirect ophthalmoscope accessories may be fitted (Hilton, 1971; Kenny, 1972).

The new battery pack has a $\mathbf{I} \cdot 8$ ampère hour capacity which is ample for a day's work. Short circuit protection and charge indication are provided. Rapid charge (within 30 min. instead of the usual $14 \mathrm{hrs}$ ) is available as an option.

\section{Discussion}

Indirect ophthalmoscopy and magnification may be combined in one of two ways: by the introduction of the magnifiers into the optical path of the ophthalmoscope, or by the use of separate optical paths which are moved individually into the line of sight as required.

The first system has the advantage of no moving parts, but its narrow angle of stereoscopy $\left(3.5^{\circ}\right)$ is inadequate for surface operative work under magnification. Its place may lie in otorhinolaryngology where a binocular magnified view into narrow cavities is theoretically attainable (Fig. 3).

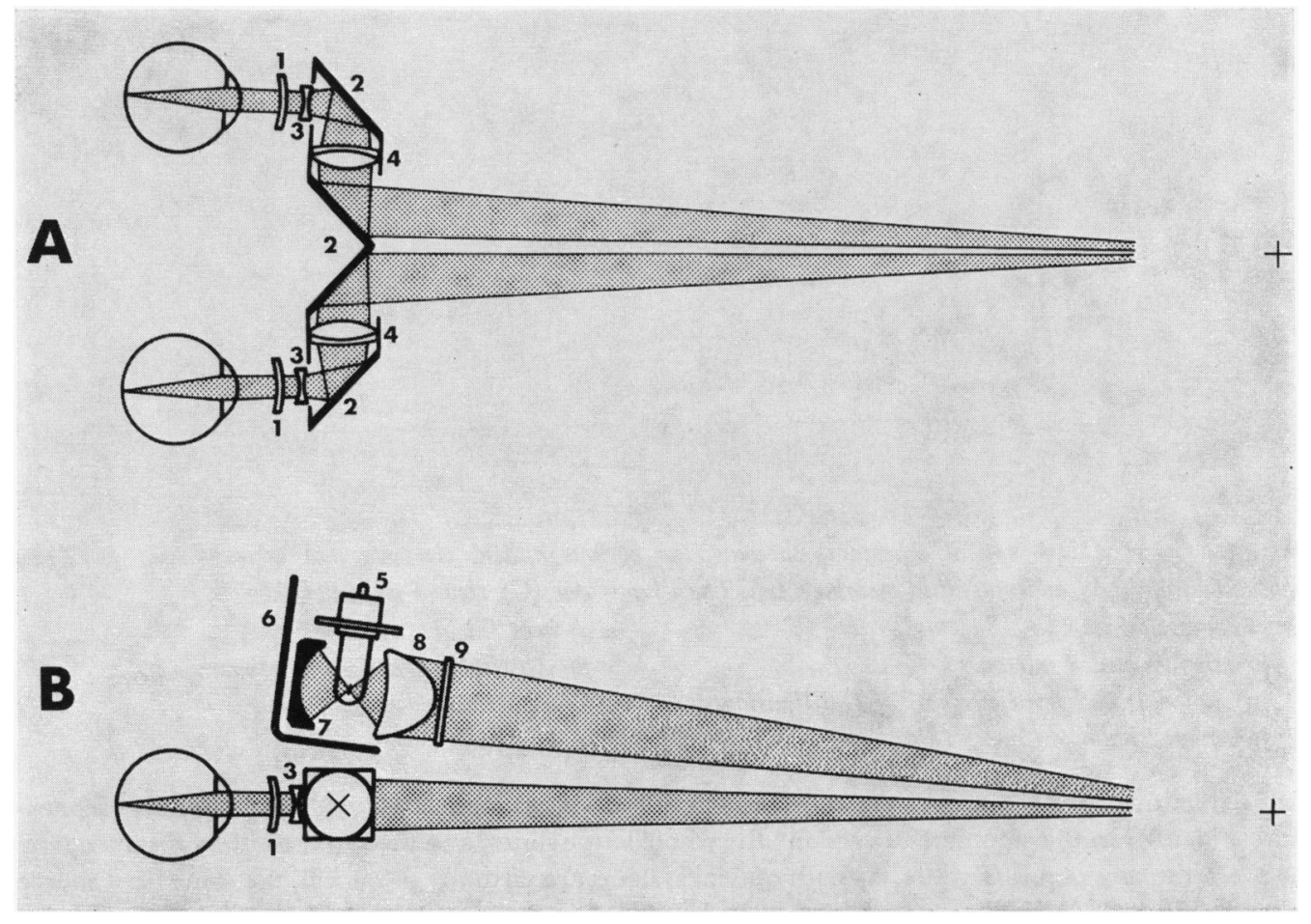

FIG. 3 Optical schemata demonstrating co-axial principle. Both systems use the same elements. $(A)$ top view. (B) side view 
The prototype of the second system has now seen extensive clinical use and has proven invaluable for retinal surgery, for the conduct of general surgical rounds, and for consulting room practice (Fig. 2).

The working distance of the loupes has been varied in different models to suit the principal user, some preferring a working distance of $250 \mathrm{~mm}$., others even $200 \mathrm{~mm}$.

The battery pack has proved sufficient for two retinal detachment operations and numerous fundus examinations in one day. Where the ocular media are clear, full illumination should be used judiciously in view of the work of Tso, Fine, and Zimmerman (1972).

The authors wish to thank Dr. R. Watkins of Sola International, Adelaide, South Australia, who has had charge of the development of the commercial model.

Their gratitude is also due to Dr. H. Maclean and Mrs. B. Vaudrey for editing this paper, and to Mr. J. Scrimgeour for the photographic illustrations.

The instrument is covered by provisional patent number PB 2456.

\section{References}

CROcK, G. W., Galbraith, J. E. K., and PARel, J.-M. (1969) Brit. F. Ophthal., 53, 356

HILton, G. F. (I97I) Arch. Ophthal. (Chicago), 85, 709

KENNY, G. s. (1972) Brit. F. Ophthal., 56, 570

RUCKER, c. w. (1972) "A History of the Ophthalmoscope". Whiting, Rochester, Minn.

TSO, M. о. M., fine, B. s., and zimmerman, L. E. (1972) Amer. F. Ophthal., 73, 686 